\title{
Ejemplos del uso de los símbolos cristianos en la vida cotidiana en Serbia
}

Milesa Stefanović-Banović *

Resumen: El regreso a la religión luego de varias décadas de secularismo y racionalismo ha traído nuevas prácticas religiosas a la vida social y cultural en Serbia. Estas transformaciones, en determinados aspectos, incluyen el regreso a la tradición religiosa pre-socialista $y$, en gran medida, crean nuevas pautas que intentan integrarse en el contexto antiguo y tradicional. Como resultado de esto aparecen muchas prácticas híbridas, que probablemente se vuelven más notorias en los ejemplos de la cultura material, como forma más común de la manifestación de la religiosidad.

Una de las características más importantes de este proceso es la hiperproducción de objetos con símbolos cristianos. La iconografía cristiana ortodoxa se utiliza en productos de uso común con énfasis en los valores materiales y estéticos, lo que resulta completamente opuesto a la esencia cristiana.

Este trabajo presentará los ejemplos de una nueva percepción de la cultura religiosa material, que comprende la comercialización de las costumbres religiosas, las excesivas demostraciones públicas de la religiosidad, la identificación de la identidad nacional y cristiana, y un cambio general del foco desde lo espiritual hacia lo material.

Palabras clave: iconografía ortodoxa - símbolos cristianos ortodoxos - sociedad contemporánea.

[Resúmenes en inglés y portugués en la página 350]

${ }^{(*)}$ Magister en Filosofía de la Universidad de Belgrado. Actualmente se desempeña como investigadora en dos proyectos del Instituto Etnográfico de la Academia Serbia de Ciencias y Artes: Estrategias de la identidad: la cultura contemporánea y la religiosidad y La investigación interdisciplinaria de la cultura serbia y el patrimonio lingüístico: la creación del portal multimedial El Lexicón de la Cultura Serbia.

\section{Introducción}

El regreso a la religión, después de varias décadas de secularización y racionalismo, ha traído nuevas prácticas religiosas a la vida social y cultural en Serbia. En cierta medida estas transformaciones suponían el regreso a las tradiciones religiosas presocialistas. Sin embargo, se generaron nuevas pautas, tratando de encajar en el contexto de lo antiguo y 
lo tradicional. Los fenómenos que han generado se vuelven notorios con mayor facilidad en los ejemplos de la cultura material como forma más frecuente de la manifestación de la religiosidad.

Los ejemplos de esta nueva percepción de la cultura material religiosa incluyen la comercialización de las necesidades y los ritos religiosos, una exagerada expresión pública de la religiosidad, al igual que un cambio general del foco de las prácticas religiosas desde lo espiritual hacia lo material.

Este trabajo delibera acerca de si tales fenómenos en verdad son resultado de las necesidades religiosas del hombre moderno, o no son más que una tendencia actual. El trabajo también examina de qué manera estos fenómenos podrían influir en la conservación de los valores tradicionales, pero también trata sobre el desarrollo cultural y espiritual general de la sociedad.

Para el presente trabajo se realizó una encuesta, con el propósito de indicar cómo tratan los ciudadanos este tema en su vida cotidiana.

\section{La expresión contemporánea de la religiosidad en Serbia}

La necesidad de expresar públicamente la afiliación a una religión o comunidad religiosa a través de varias formas materiales es tan antigua como la sociedad humana. Se manifiesta con más frecuencia en forma de visitas a los lugares sagrados, turismo religioso y prácticas de peregrinación, y también llevando los símbolos religiosos en forma de adornos, joyas, incluso teniendo objetos de uso común con estos símbolos, pero también tatuando los símbolos religiosos en la piel. En cada cultura y religión, estos fenómenos se manifiestan de una manera específica y en formas específicas. El cristianismo, sin duda, no es una excepción. Durante la época de la Yugoslavia comunista, entre 1945 y 1990, la iglesia y la religiosidad en general fueron sistemáticamente marginalizadas. En este período la educación religiosa fue bastante descuidada. Después de la desintegración del Estado Federal, junto con el despertar de la conciencia nacional, la religión experimentó una revitalización repentina y masiva. Debido a la insuficiente educación religiosa, este fue el momento en que algunos elementos, que ni siquiera se basaban en la tradición cristiana, obtuvieron una influencia importante. En la búsqueda de la tradición olvidada, pero también a menudo inventada, los elementos ortodoxos algunas veces perdían su función básica, religiosa, y sus propiedades nacionales, mágicas y estéticas eran enfatizadas.

Este periodo de re-concientización nacional y religiosa se caracterizaba por la popularización de la expresión pública de la religiosidad. Se manifiesta a través del énfasis de los símbolos ortodoxos, visitas intensificadas a los monasterios y lugares sagrados donde se otorgan numerosos regalos y se donan artefactos religiosos onerosos, gran número de bodas, bautismos, funerales religiosos, etc.

El masivo regreso a la religión tuvo como resultado la hiperproducción de los objetos con los símbolos religiosos e iconográficos (Blagojević 2011: 225). Los más frecuentes entre ellos, y los que más se demandan, son las cruces, los rosarios, las joyas y los íconos. Además de esto, la iconografía ortodoxa se utiliza también para los objetos de uso común, como encendedores, servilletas, manteles, imanes para heladeras, colgantes, ropa, gafas, botellas, etc. 
Es importante mencionar que los fenómenos mencionados no son una característica excepcional de la gente serbia y los creyentes ortodoxos. También se pueden encontrar entre otras naciones y religiones en el territorio de la ex Yugoslavia; sin embargo, esto supera el ámbito de este trabajo.

Aunque la tendencia de la secularización de la sociedad serbia en el período (pos) transicional implica una disminución de la euforia religiosa desde los noventa, todos los fenómenos mencionados todavía están presentes, aunque en menor medida. Así, los íconos se pueden encontrar en las cafeterías, casinos y discotecas, en las tarjetas de crédito y telefónicas, en las botellas de cerveza; los restaurantes, clubs deportivos y consultorios veterinarios que llevan nombres de diferentes santos, etc. (Pavićević, 2005: 194-195).

El uso de los símbolos ortodoxos al contrario de su esencia y tradición cristiana puede ser más perceptible en los ejemplos de los individuos en la esfera de la vida pública. Las "estrellas" del espectáculo, deportes y medios de comunicación, con diferentes motivos, usan estos símbolos en sus apariencias públicas y tienen gran influencia en la juventud, pero también en el completo clima espiritual en el país. El poder adquisitivo de estas estrellas y nuevas élites en Serbia tuvo como resultado un gran valor material de los artefactos religiosos (las cruces y los íconos creados en oro, adornados con piedras preciosas etc.) [Ver Figura 1 en Catálogo de Figuras en página 347].

Considerando valores y virtudes cristianos tradicionales, estos símbolos raras veces se usan de una manera completamente inapropiada, hasta vulgar. En este trabajo analizaré solamente casos visuales del uso de los símbolos religiosos por ciertas figuras públicas. Las entrevistas con la gente de este ámbito y sus motivos seguramente podrían abordar un tema antropológico separado e importante.

\section{La metodología de la encuesta}

La encuesta realizada con el fin de este trabajo tuvo como objetivo indicar cómo tratan los ciudadanos la cultura material religiosa en su vida cotidiana. Los cuestionarios fueron organizados en parte en forma de entrevistas, y por otra parte se encontraban disponibles para todos los interesados en una página web.

Se puede decir que la muestra fue escogida al azar, es decir los entrevistados fueron seleccionados sin ningún criterio particular; en lugar de eso, el cuestionario estuvo abierto y disponible para cualquiera que estuviera interesado. En total, fueron 57 personas las que participaron de la encuesta. Fue realizada en Belgrado, Novi Sad, Šid, Zaječar y Kragujevac. El principal criterio en la selección regional fue la viabilidad técnica, aunque la intención era que el número de encuestados fuera aproximadamente proporcional a la población de cada área. Así que 39 personas fueron encuestadas en Belgrado (68\% de los encuestados), 7 en Novi Sad (12\%), 4 en Šid (7\%), 4 en Kragujevac (6\%) y 3 en Zaječar (5\%). 2

Estas ciudades fueron seleccionadas para representar diferentes regiones de Serbia: la Ciudad de Belgrado, Novi Sad en la provincia norteña Voivodina, Šid en la region del oeste Srem, Zaječar en este de Serbia, y Kragujevac en la region de Šumadija, en Serbia Central. Debido a la viabilidad técnica, algunas regiones de Serbia no pudieron incluirse en la encuesta. Además, la encuesta se centró sólo en áreas urbanas. 
Los encuestados nacieron entre 1951 y 1990, de los cuales 28 eran hombres y 29 mujeres. No hubo ningún criterio particular en la selección de la edad, pero el método de la realización de la encuesta, expuesto en el texto que sigue, suponía que la mayoría de los encuestados fueran técnicamente alfabetizados e interesados en el tema de la investigación. Las entrevistas directas fueron realizadas con 15 individuos, seleccionados de un gran círculo de conocidos. Aunque la muestra no se puede considerar representativa, los resultados no muestran ninguna correlación de actitudes dentro de este grupo de encuestados. La otra, mayor cantidad de datos se obtuvo a través de una encuesta abierta, por internet, la cual fue completada por 42 encuestados. Se pedía a cada uno de los encuestados que enviara la encuesta a cualquier persona que pudiera estar interesada en este tema. Este método ha creado un modelo de distribución viral, que permite el crecimiento exponencial del número de informantes con la difusión de la encuesta. Así, cualquier correlación social entre los informantes se debilita con nuevos envíos.

Esta metodología de encuesta, hay que admitir que dio lugar a un cierto error sistemático, que se refleja en la estructura de la edad y formación de los encuestados. La mayoría de los encuestados, el 77\% no tenía aún 30 años, y el 62\% contaba con educación superior. Sin embargo, ninguna segregación significante de las actitudes se puede notar a base de la estructura educacional.

Entre los encuestados, cinco de ellos tenían educación teológica, cuyas actitudes, como es lógico, muestran un modelo determinado por su interés y conocimiento de la teología ortodoxa. La comparación de las respuestas de este grupo con los de otros grupos puede ayudar en el análisis acerca del efecto que tiene la postura oficial de la Iglesia sobre la formación de las actitudes laicas.

Hasta 49 encuestados declararon que eran religiosos. Entre ellos había 47 ortodoxos, un católico romano y uno que se declaró creyente "cristiano". El número de los creyentes activos era 26, mientras 23 encuestados eran creyentes inactivos (tradicionales). ${ }^{3}$

Según las recomendaciones de Bourdieu (Bourdieu 2004: 88-114) con respecto a la objetivación del método científico, me gustaría destacar que soy completamente consciente de la posible influencia de las normas culturales, estéticas y otras, y de las actitudes religiosas de mi entorno social, sobre la objetividad de la investigación. Los resultados obtenidos han sido analizados sin conclusiones que podrían ser afectadas por estas normas sociales, sino únicamente en el sentido de la observación del uso contemporáneo de los artefactos cristianos al contrario de su uso tradicional, y a menudo con la esencia cristiana también.

\section{Los resultados de la encuesta}

La mayoría de los encuestados (52\%) cree que los símbolos religiosos y los nacionales no se podrían equiparar, y las respuestas varían desde moderadas, ej. "en nuestro país muchas cosas se equiparan con la Iglesia, pero yo creo que esos son dos asuntos diferentes; hay serbios católicos y musulmanes también", hasta las más extremas, ej. "la equiparación de la religión y la nación es devastadora, es una actitud completamente simplificada sobre la religiosidad, su reducción a la tradición e ideología". Un $9 \%$ de los encuestados cree que los símbolos religiosos en la mayoría de los casos no representan símbolos nacionales, 
pero que algunos de ellos, como los santos serbios, los santos patronos de las familias ${ }^{4}$ o la cruz en el escudo de armas nacional y la corona se pueden considerar al mismo tiempo tanto símbolos ortodoxos como nacionales. El escudo de armas del Estado (un escudo con una cruz) y la bandera, en la que también está representado, son los ejemplos citados con mayor frecuencia.

La mayoría de los encuestados (81\%) afirmó que había llevado algún tipo de símbolo religioso. En la mayoría de los casos se trataba de los rosarios (39\%) y joyas con una cruz o un ícono (24\%). Un encuestado dijo que tenía "poderes de un lugar sagrado" por sí mismo, mientras que el otro llevaba "tres cruces de tres lugares sagrados". Uno dijo que tenía un tatuaje porque eso "es cool, y atractivo también". Lo que resulta interesante es que tres de los encuestados, que se habían declarado ateos, dijeron que llevaban algún símbolo ortodoxo u otro.

Las razones por las que llevan cruces, rosarios y joyas con los símbolos religiosos, se pueden dividir en dos grupos. El primer grupo abarca los motivos de naturaleza religiosa, mientras que el otro abarca aquellos que no son completamente de carácter religioso, o no tienen nada de carácter religioso.

Los motivos impulsados por la religión son bastante diferentes: "por la fe" o "por la religiosidad" (7); "la cruz es la salvación"; "por mi fe en la Iglesia"; "para dirigirse a Dios" (3); "para la oración" (5); "para el Señor y la madre de Dios (Theotokos)"; "para recordar la bondad y los sufrimientos de Cristo"; porque "me recuerda siempre cómo debería vivir la vida"; o porque estos objetos "facilitan la salvación".

Los encuestados cuyos motivos no eran estrictamente religiosos se pueden dividir asimismo en tres subgrupos. El primero abarca aquellos cuyos motivos para llevar símbolos ortodoxos son más de naturaleza simbólica que espiritual. Así, su motivación no es por razones personales, espirituales, sino mas bien resulta del deseo de promover ciertos símbolos (valores) religiosos en público. Las respuestas más características de este grupo son: "yo creo en lo que soy"; "porque quiero a mi gente"; "por la identidad"; "la señal del pueblo serbio"; "cualquiera que sea creyente debería llevarlo"; y "la cruz representa el poder y el símbolo".

El segundo subgrupo abarca los encuestados que están conscientes del sentido religioso de estos símbolos. Sin embargo, su relación con estos objetos tiene un carácter mágico en cierto modo. Ellos creen en el poder de la cruz, y creen que el santo de un ícono, al oír la oración, ejercerá el poder sobre los desarrollos naturales y las tendencias sociales, en beneficio del que reza (Blagojević 2011: 230). Los símbolos religiosos dan "la sensación de seguridad" (7), "tienen poder", "dan fuerza" (2), traen suerte, protegen del mal, mientras que tres encuestados llevan colgantes con los íconos de los santos por protección (4). Un encuestado dice que lleva un símbolo religioso porque "fue consagrado como regalo de la Iglesia”.

El tercer subgrupo abarca las respuestas de los encuestados cuyos motivos no son de carácter religioso, sino solamente de carácter emocional o estético: "es un regalo de mi novia, la fe en el amor"; "me gusta, y me gusta llevar algo mío"; "pienso que se ve bonito"; y "porque es cool'.

Se sabe que en las culturas antiguas y tradicionales la decoración del cuerpo se practicaba desde hace miles de años por razones sociales, religiosas, estéticas, por costumbre y por 
salud. En la cultura serbia también nos encontramos con esto. Se cree que la decoración del cuerpo proporciona la protección de los ojos malvados y hechiceros. En la actualidad, el intensificado uso de los objetos religiosos ha coincidido con la tendencia global de la decoración del cuerpo, con tatuajes, piercing, etc. Sin embargo, algunos autores creen que la decoración del cuerpo en la cultura moderna tiene su origen en las subculturas basadas en las tendencias contradictorias de individualización y afiliación. Por otra parte, esta manera de manifestar la identidad religiosa es completamente contraria al Cristianismo.

Si existen unos inconscientes contenidos mágico-religiosos escondidos en el simbolismo mitológico como un factor estético, entonces los símbolos religiosos manifestados como medio de la decoración del cuerpo muestran como el paganismo se manifiesta incluso a través de los contenidos cristianos (Jovanović, 2009: 27-40).

Por lo tanto, el modo en el que los encuestados valoran los símbolos religiosos -en caso de que se basen principalmente en motivos estéticos, espirituales u otros- nos interesa en esta investigación [Ver Figura 2 en Catálogo de Figuras en página 347].

Cuando fueron preguntados acerca de si era importante que los objetos religiosos que llevaban tuvieran un valor estético, es decir si intentaban ajustarlos con la ropa que llevaban puesta, $17 \%$ de los encuestados respondió afirmativamente, mientras que 39\% dice que los valores estéticos no tienen ninguna importancia para ellos. Más detalladamente: "cada símbolo cristiano también tiene un valor estético por sí mismo"; "solamente es necesario que me guste"; "es muy fácil ajustar estos detalles con la ropa"; "el valor estético (es importante) en cierto modo, yo no los combino con otras partes de la ropa"; "sí, tengo rosarios en varios colores, y normalmente trato de combinarlos bien con lo que llevo puesto" [Ver Figura 3 en Catálogo de Figuras en página 347].

Una forma de comercialización de los símbolos religiosos se puede notar en el ejemplo de los vehículos. Hasta un 33\% de los encuestados tiene algún símbolo cristiano en su auto, mientras que los demás o no tienen estos símbolos en sus autos, o ni siquiera tienen un auto. Los motivos para tener símbolos religiosos en los vehículos son similares a los que hemos mencionado para el resto de los objetos portables. Los encuestados que tienen símbolos religiosos en sus vehículos los tienen principalmente porque les dan una sensación de seguridad y protección de Dios. Un encuestado respondió: "Me gusta tener un símbolo religioso en un lugar donde lo pueda ver siempre (casa, coche, etc.) y es importante para mí", mientras el otro dijo: "porque respeto a mi familia, que es muy religiosa, y por la espiritualidad como un aspecto muy importante del ser humano". Otra respuesta interesante es: "(en mi auto) tengo un rosario con una cruz para que me recuerde a la oración y a buenos modales en tráfico". Sólo tres encuestados no exponen públicamente los símbolos religiosos: "tengo un ícono de un santo, no en un lugar visible, sino en mi carné de conducir, por las mismas razones por las que tengo un ícono en casa".

Los objetos religiosos en los vehículos en la mayoría de los casos cuelgan del espejo retrovisor. En 18 casos respectivos se trataba de una cruz o un ícono, en seis casos de rosarios, mientras que en cuatro casos había oraciones para los conductores y pasajeros. Hubo dos respuestas particulares: "un colgante, porque es un regalo" y "una alfombrita, porque ya 
estaba en el auto". Los encuestados frecuentemente decían que tenían varios objetos religiosos en sus coches. En la mayoría de los casos se trataba de una cruz y un ícono (9\%), mientras que otros casos respectivamente incluían una cruz y un rosario, un rosario y un ícono, al igual que estos tres objetos religiosos juntos.

El modo de valorar las piezas religiosas -es decir, su calificación como nacionales, estéticas o religiosas-se puede buscar en la respuesta de los encuestados a la pregunta sobre el valor material de los objetos con simbolismo religioso.

Casi todos los encuestados, excepto ocho, afirmaron que asignaban la misma importancia a todos los objetos religiosos, independientemente de su valor material. Algunos encuestados claramente distinguían el valor estético del religioso, y una parte de ellos asigna a los objetos religiosos principalmente la importancia espiritual: "valoro su atractivo estético, independientemente del material del que están hechos"; "creo que lo que importa en un ícono no es su valor material, pero esto no significa que yo no respeto y aprecio algunos objetos religiosos más valiosos; con esto me refiero a los íconos hechos a mano"; "claro que me gustan los íconos hechos a mano, pero siento el mismo arrebatamiento religioso ante aquellos hechos con medios bastante modestos"; "los íconos hechos a mano son más bonitos, pero eso no necesariamente los hace más valiosos". En el segundo grupo se ha notado mayor aprecio por los objetos hechos a mano, como objetos con un valor adicional por el labor y el tiempo invertidos en su manufactura: "valoro más los íconos hechos a mano porque sé que alguien ha invertido su tiempo y esfuerzo en hacerlos, al igual que su talento y determinación"; "los productos hechos a mano se manufacturan durante el ayuno, y tienen un valor mayor"; "lo aprecio cuando alguien lo hace desde su alma". También está presente la conciencia del hecho de que la compra de los objetos religiosos representa al mismo tiempo una donación a la Iglesia: "doy prioridad a los artefactos hechos a mano, manufacturados por los sacerdotes, monjes, u otras personas espirituales (...) comprándolos, nosotros apoyamos la existencia de instalaciones religiosas y del espíritu de la fe entre la gente".

En la vida cotidiana serbia existen muchos ejemplos en los que los objetos preciosos son usados para la identificación social. Este modo de identificación ha creado, a lo largo del tiempo, unos modelos estereotípicos de la percepción colectiva. Por ejemplo, se supone que los individuos que llevan unas joyas caras con los símbolos religiosos, como grandes cruces de oro o de diamantes en valiosas cadenas de oro, se asocian con los círculos criminales o de música folk.

Uno de muchos ejemplos que ilustran los productos hechos al gusto de la "nueva elite", pero aceptados generalmente, podría ser la colección recién lanzada de rosarios hechos de metales y piedras preciosos (www.facebook.com/BeUniqueBePure). La aparición de las joyas en el mercado apela al sentimiento religioso del consumidor en diferentes maneras. Su nombre, "Sé único - sé puro", implica la purificación espiritual que se conseguirá con la simple posesión de alguna pieza de la colección. Esto se enfatiza con el presunto "apoyo de la Iglesia Ortodoxa Serbia" a través del certificado obtenido de la Iglesia. El motivo nacional también está presente porque las joyas se califican como "tradicionales serbias". Además, como una de sus principales promotoras fue seleccionada una famosa cantante de música folk, cuyo nombre a menudo se menciona en el contexto nacional y a veces en el criminal. Cierto número de encuestados criticó el abuso de los símbolos religiosos y su uso total- 
mente opuesto al espíritu del cristianismo: "el cristianismo nos enseña que la modestia es una virtud, y por eso yo valoro más los íconos de papel, o los cruces e íconos hechos a mano; los objetos grandes hechos de oro son, en mi opinión, demasiado adornados y de mal gusto, por lo que ni los prefiero ni me gustan"; "los primeros íconos (de papel) son de mayor valor"; "yo valoro todo de la misma manera, sólo que de ver las cruces gigantes en algunos coches se me pone la piel de gallina, es muy lamentable que alguien piense que espiritualmente está en una mejor posición porque tiene una cruz gigante"; "yo no (los valoro de la misma manera), porque tales objetos son frecuentemente abusados por fines comerciales". Un encuestado destaca la naturaleza poco práctica de los íconos hechos de materiales más baratos: "no, yo no (los) valoro, yo incluso prohibiría esos pequeños íconos de papel, porque no son prácticos". Otro encuestado resalta la dimensión subjetiva de los artefactos religiosos: "cada objeto tiene su propio valor, pero también un valor subjetivo, según lo que significa para mí y a lo que lo asocio; por ejemplo, puede ser algo que yo haya recibido de alguien cercano y querido, o que haya conseguido de una manera que lo hace importante".

Durante los noventa los símbolos religiosos fueron comercializados, lo que contribuyó en gran parte al surgimiento de la nueva cultura material. Como ya se ha mencionado, una de sus principales características también era la separación de la esencia ortodoxa de los símbolos religiosos de su uso. En casos extremos, este proceso tuvo como resultado los símbolos ortodoxos puestos en los objetos de uso común, no religioso, como encendedores, imanes para heladeras, abrebotellas, etc. Objetos relacionados con los santos patronos de la familia (Kalezić, 2000) que no tienen absolutamente nada que ver con el rito religioso, sino que son estrictamente de naturaleza utilitaria, son especialmente perceptibles. Estos principalmente son vasos, botellas, servilletas, platos, manteles, candelabros, bolsas de papel, y otros objetos que se consideran decoración "apropiada" para el día del santo patrono de la familia.

Desde el punto de vista teológico, el ícono es una "forma visual de oración” y por lo tanto sus propiedades materiales deberían ser irrelevantes comparadas con su fin religioso. ${ }^{5}$ Según la tradición cristiana, todos los íconos tienen el mismo valor espiritual y se consideran representaciones de los santos. ${ }^{6}$ Por lo tanto, el hecho de que estos objetos sean de naturaleza desechable o para un sólo uso, por lo que en la mayoría de los casos terminan en los tachos de basura, es el mayor problema. Es importante mencionar que estos objetos no se pueden comprar en las iglesias o en las tiendas eclesiásticas; sin embargo, es evidente también que la Iglesia no tiene la suficiente fuerza o autoridad para prevenir la degradante producción de estos objetos, que se han convertido en sinónimos de mal gusto, y que frecuentemente se ridiculizan [Ver Figura 4 en Catálogo de Figuras en página 347].

Hasta un 30\% de los encuestados afirmó que utilizaba objetos de uso común con símbolos religiosos, principalmente para la celebración del día del santo patrono de la familia, en su propia casa o cuando visitan a alguien. Cuando organizan la celebración del día del santo patrono de la familia, utilizan "servilletas, manteles, botellas, todo para la fiesta de la familia". Los objetos religiosos se usan "para que todo sea de la misma esencia/espíritu", e "intentamos celebrar ese día (del santo patrono de la familia) de manera que todo esté dedicado al santo patrono de nuestra familia y nuestra casa". Los objetos que con más 
frecuencia se encuentran en los hogares son las botellas en las que se hallan representados los santos patronos de las familias (6 casos), mientras que en un caso hubo también un candelabro con la imagen del santo patrono. Unos nueve encuestados dijeron que cuando visitaban a la gente en ocasiones de celebración del día del santo patrono, siempre llevaban bolsas u otro tipo de envase con las imágenes del santo.

Aun así, la mayoría de los encuestados (54\%) no usa otros objetos con iconografía ortodoxa. Ellos dan razones de naturaleza estética y espiritual: "todo termina en la basura"; "los íconos y las cruces y algunos símbolos apropiados, todo lo demás me parece una vulgarización de los sentimientos religiosos"; "el sentimiento de lo sagrado está perdido"; "creo que eso está pasando los limites, y que las imágenes no deberían usarse literalmente para todo"; "lo encuentro kitsch".

\section{Conclusión}

La comercialización de la religión es un fenómeno de naturaleza global. Aunque aparece en formas específicas de una zona determinada, también muestra algunas propiedades comunes a nivel global, de las cuales la más evidente y ubicua es el cambio cultural hacia lo material.

Por ejemplo, en Japón, sobre el 70\% de todos los matrimonios se ha llevado a cabo en santuarios sintoístas. Estas bodas de estilo shinzenshiki representan la mayor fuente de ingresos de estos santuarios y por lo tanto se anuncian frecuentemente, con argumentos de antigüedad y tradición auténtica (Antoni 2001). En Croacia, Medjugorje es otro ejemplo de la peregrinacion como principal poder económico del área. Desde la primera aparición de la Virgen María en 1981, a pesar de la actitud oficial reservada de la Iglesia católica, esta zona ha sido visitada por millones de peregrinos, lo que ha afectado en gran medida la economía de toda esa región (Vukonić, 1992). En Cuba, la herencia religiosa afro-cubana ha sido reconocida como un asunto importante en sentido económico y político. Se han creado instituciones especializadas para protegerla, y así se ha generado un enlace, que antes no existía, entre la religión, la herencia y el turismo, con la comercialización que en este enlace tiene un papel importante (Perez, 2010). La herencia religiosa y cultural americana autóctona también ha sido reconocida como una oportunidad de negocio. Los euro-americanos se han beneficiado de las publicaciones y talleres basados en la espiritualidad americana autóctona. La producción masiva de "los objetos sagrados americanos autóctonos" fue vendida al mercado en gran parte no indio (Aldred, 2000). Uno de los ejemplos más representativos viene de Nigeria, el país que tiene más iglesias per cápita en el mundo. Debido a la pobreza, los pastores, a menudo muy mal pagos, están tentados de utilizar su posición para su beneficio económico. Algunos de ellos organizan programas con títulos atractivos, como "Fórmula de Dios para el éxito y la prosperidad", usado para reunir donaciones. Algunos utilizan pasajes de Biblia o salmos retorcidos para amenazar a los creyentes, y ofrecen "oraciones especiales" como alivio, vendiendo velas especiales y otro material necesario para estos ritos (Ogunkunle, 2011).

Aunque lejos de tales extremos, las prácticas religiosas en Serbia también encajan en la 
tendencia global de comercialización y materialización. Los resultados de la encuesta indican que el fenómeno de la Serbia (post)-transicional que surge con el desarrollo de la nueva cultura material desde el año 1990, todavía existe.

Existe una extendida comercialización de los objetos religiosos que, según los resultados de la investigación, no se puede relacionar con ningún grupo homogéneo en particular. Los resultados confirman la heterogeneización de diferentes tipos de la religiosidad y relaciones con los símbolos religiosos, con solapamiento, mezcla y cambio de papeles entre los símbolos sagrados y seculares, que, por otra parte, es una propiedad común de la situación contemporánea.

Además, es evidente la falta de trabajo misionero de la Iglesia en este campo, lo que contribuye al abuso y divergencia del principal objetivo cristiano de estos símbolos religiosos. Cuando digo esto, pienso en primer lugar, en los encuestados que afirmaron que sus motivos para el uso de los símbolos religiosos eran estrictamente de naturaleza teológica. Los acontecimientos en las prácticas religiosas que se han tratado en este trabajo no son un nuevo fenómeno, ni en el nivel local ni en el global. El carácter de este fenómeno es más de naturaleza cíclica que temporal. Cuándo ocurrirán, cómo y por cuánto tiempo se manifestarán, depende de varios factores, de los cuales las condiciones políticas y económicas son unos de los más importantes. Las percepciones y manifestaciones de la religiosidad son un reflejo del estado general de la sociedad.

Los resultados de la investigación muestran que las actitudes de los encuestados no están correlacionadas ni con sus perfiles religiosos, ni con los educativos. Existe una evidente necesidad de la expresión pública de la religiosidad, inspirada por motivos personales muy diferentes. Sin embargo, hay que tener en cuenta que las tendencias modernas influyen en esta motivación. No es posible trazar una línea clara entre lo individual y lo colectivo. Se puede decir que las tradiciones cristianas diferentes o percibidas de diferentes maneras, más que el propio Cristianismo, se han convertido en una parte inseparable de la sociedad (pos) moderna de Serbia.

\section{Notas}

1. Este trabajo es el resultado de la investigación en el proyecto número 177028: Strategije identiteta: savremena kultura i religioznost (Estrategias de la identidad: la cultura y la religiosidad contemporánea), financiado por el Ministerio de Ciencia de la República Serbia.

2. Según los resultados del censo serbio de 2011, el número de habitantes en las regiones seleccionadas es: Belgrado 1,731,425; Novi Sad 359,951; Kragujevac 188,809; Šid 35,470; Zaječar 126,845 (SORS 2011). Cuando se compara el número de habitantes de cada región seleccionada con el número total de habitantes en todas las regiones seleccionadas, se obtiene el siguiente porcentaje: Belgrado 70,89\%, Novi Sad 14,74\%, Kragujevac 7.73\%, Šid $1.45 \%$, Zaječar 5.19\%.

3. Bajo "creyentes activos" comprendo los encuestados que empezaron a participar en los oficios de la iglesia o atendían los sermones regularmente, mientras que bajo la expresión "creyentes inactivos" pienso en los que se declararon creyentes, pero participan en los oficios de la iglesia o atienden los sermones sólo en contadas ocasiones, o nunca. 
4. Slava es la tradición serbia ortodoxa que consiste en la celebración ritual y la veneración del santo patrono de la propia familia. La familia celebra slava una vez al año en la fecha o el día del santo patrono. La celebración incluye el ritual del pan consagrado y koljivo (trigo cocido, normalmente bien molido, con nueces, pasas y miel añadidos) que realiza el sacerdote en casa o en la iglesia, seguido con la comida para la familia, parientes y amigos. 5. "Desde el punto de vista ortodoxo, el ícono representa una forma visual de oración. El papel del arte eclesiástico es establecer la viva presencia de Cristo y de los Santos dentro de la Sagrada Comunión. Entonces, el papel de la pintura es de naturaleza ontológica, antes que decorativa." (Skliris, 2005: 170; Bigović, 2007: 7)

6. "Un ícono representa la personalidad - es una hipostasis de su original y tiene su nombre. De ese modo el respeto que se muestra hacia el contenido del ícono se transfiere al original." (Đurić, 2010: 29).

\section{Referencias Bibliográficas}

Aldred, L. (2000). Plastic Shamans and Astroturf Sun Dances. New Age Commercialization of Native American Spirituality. American Indian Quarterly. vol. 24, no. 3, p. 329. University of Nebraska

Antoni, K. (2001). Religion and Commercialization: The Shinto wedding ritual (shinzenshiki) as an "Invented tradition" in Japan. Japanese religions. vol. 26, p. 41-53. ISSN 04488954.

Bigović, R. (2007). Mornari neba [Los marineros del cielo]. Belgrado: Hrišćanski kulturnicentar.

Blagojević, G. (2011). Ikona kao roba: jedna ilustracija pravoslavnog identiteta u Srbiji danas [Icono como mercancía: una ilustración de la identidad ortodoxa en Serbia hoy]. Antropologija, religije i alternativne religije - kultura identiteta [Antropología, religiones y religiones alternativas - la cultura de la identidad]. Belgrado: Srpski genealoški centar.

Đurić, Ž. (2010). Bogoslovlje ikone [Teología del icono]. Živopis. vol. 4, p. 23-30. Belgrado. Jovanović, B. (2009). Estetsko pre-oblikovanje tela [Re-formación estética del cuerpo]. Tradicionalna estetska kultura: Telo i odevanje [La cultura estética tradicional: el cuerpo y las maneras de estir]. 2009, vol. 3, p. 27-40. Niš: Centar za nau na istraživanja SANU, Univerzitet u Nišu

Malešević, M. (2011). Ima li nacija na planeti Ribok? Ogledi o politikama identiteta. [¿Hay naciones en el planeta Reebok? Ensayos sobre politicas de la identidad]. Belgrado: Srpski genealoški centar.

Ogunkunle, C. O. (2011). Commercialization of religion in Nigeria: The Christian perspective. Issues in the practice of religion in Nigeria. pp. 301-303. University of Ilorin, Nigeria.

Pavićević, A. (2005). Šta radi i gde sedi Beli anđeo? [¿Qué hace y dónde está sentado el angel blanco?]. Glasnik Etnografskog instituta SANU, vol. 53, p. 187-194. Belgrado: SANU.

Perez Amores, G. (2010). Orishas, tourists and practitioners. The commercialization of religious heritage in Cuba: an example of revitalization strategy and economic identity. $P A-$ SOS: Revista de Turismo y Patrimonio Cultural. vol. 8, no. 1, p. 167-184. ISSN 1695-7121. 
Skliris, S. (2005). U ogledalu zagonetki [En el espejo de las adivinanzas]. Belgrado: Pravos lavni bogoslovski fakultet SPC.

SORS (Statistical Office of the Republic of Serbia). (2011). Census of Population, Households and Dwellings in the Republic of Serbia: First results. Avaliable on: http://media. popis2011.stat.rs/2011/prvi-rezultati.pdf (last accessed 1.9.2012).

Vukonić, B. (1992). Medjugorje's religion and tourism connection. Annals of Tourism Research. vol. 19, no. 1, p. 79-91.

\section{Bibliografía}

Berger, P. (1999). The Desecularization of the World: Resurgent Religion and World Politics. Michigan: William B. Eerdmans Publishing Company.

Bourdieu, P. (2004). Science of Science and Reflexivity. Chicago: The University of Chicago Press.

Elliade, M. (2003). Sveto i profano [Lo sagrado and lo profano]. Traducción de francés a serbio por Zoran Stojanović. Sremski Karlovci - Novi Sad: Izdavačka knjižarnica Zorana Stojanovića. (Título original: Le Sacré et le Profane. Paris: Éditions Gallimard. 1972.)

Eriksen, T. H. (2004). Etnicitet i nacionalizam [Ethnicity and Nationalism]. Traduccion de inglés a serbio por Aleksandra Bajazetov-Vučen. Belgrado: Krug. (Título original: Ethnicity and Nationalism. Virginia: Pluto Press, London\&Sterling. 2002.)

Kalezić, D. (1992). Krsne slave u Srba [Los santos patronos de las familias entre los serbios]. Belgrado: Neven.

Smith, A. D. (2010). Nacionalni identitet [Identidad nacional]. Traduccion de inglés a serbio por Slobodan Đorđević. Belgrado: Krug. (Título original: National identity, Penguin Books. 1991.)

Šućur, Dragan. (2009). Banjalučka eparhija za vreme episkopa dr Vasilija (Kostića): $1947-$ 1961 [Diócesis de Banja Luka en tiempo del obispo dr. Vasilije (Kostić): 1947-1961]. Banja Luka: Svetosavska omladinska zajednica SPC Eparhije banjalučke. 


\section{Catálogo de Figuras}

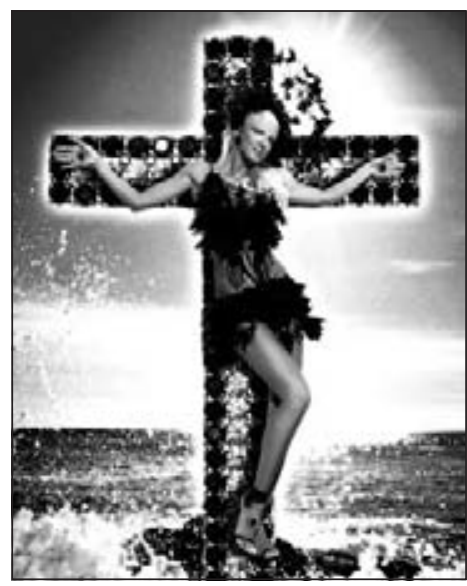

F1.

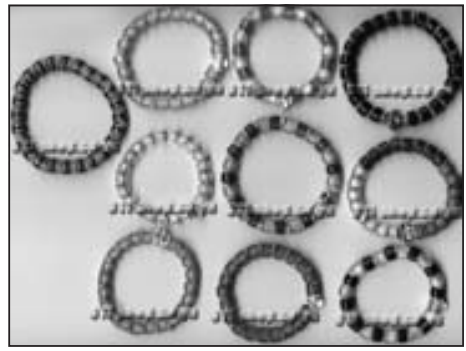

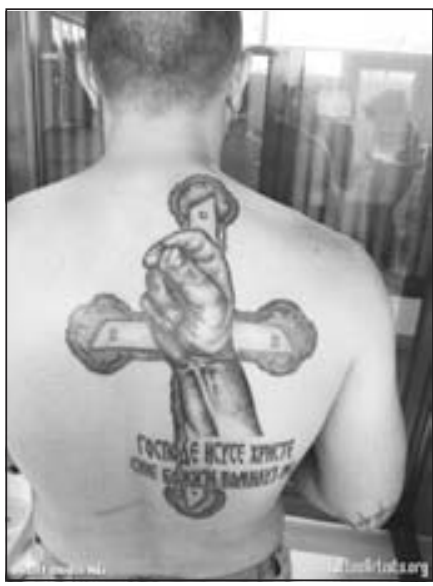

F2.

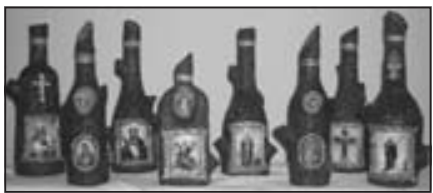

F4.

F3.

Figura 1. La cantante crucificada. Fuente. www.tracara.com/wp-content/uploads/2008/ 11/jelena_karleusa_razapeta-na-krst.jpg

Figura 2. Tatuaje. Fuente. www.tattooartists.org/Images/FullSize/000229000/Img229168 _krst_i_tri_prsta.jpg

Figura 3. Rosario-pulsera Fuente. www.shop.oaza.rs/user/include/011/images/items/bro janice-perle.png

Figura 4. Botellas. Fuente. www.oglasi.rs/images/oglas/201209/527948/1.jpg 
Summary: The return to religion after decades of secularism and rationalism has brought new religious practices to the social and cultural life in Serbia. These transformations, in certain aspects, including the return to the pre-socialist religious tradition and to a large extent, created new guidelines that seek to integrate into the old traditional context. As a result, many practices are hybrid, which probably become more noticeable in the examples of material culture, as the most common manifestation of religiosity.

One of the most important features of this process is the overproduction of objects with christian symbols. Orthodox Christian iconography used in common products with emphasis on materials and aesthetic values, which is completely opposite to the Christian essence. This paper will present examples of a new perception of religious culture material, which includes the marketing of religious customs, excessive public displays of religiosity, the identification of national identity and Christian, and a general shift of focus from the spiritual toward the material.

Keywords: contemporary society - orthodox christian symbols - orthodox iconography.

Resumo: A volta à religião depois de várias décadas de secularismo e racionalismo trouxe novas práticas religiosas à vida social e cultural em Sérvia. Estas transformações, em determinados aspectos, incluem a volta à tradição religiosa pré-socialista e, em grande medida, criam novas pautas que intentam integrar-se no contexto antigo e tradicional. Como resultado, aparecem muitas práticas híbridas, que provavelmente voltam-se mais notórias nos exemplos da cultura material, como forma mais comum da manifestação da religiosidade. Uma das características mais importantes deste processo é a hiperprodução de objetos com símbolos cristãos. A iconografia cristã ortodoxa se utiliza em produtos de uso comum com ênfase nos valores materiais e estéticos, o que resulta completamente oposto à essência cristã.

Este trabalho apresentará os exemplos de uma nova percepção da cultura religiosa material, que compreende a comercialização dos costumes religiosos, as excessivas demonstrações públicas da religiosidade, a identificação da identidade nacional e cristã, e uma mudança geral do foco desde o espiritual para o material.

Palavras chave: iconografia ortodoxa - símbolos cristãos ortodoxos - sociedade contemporânea. 